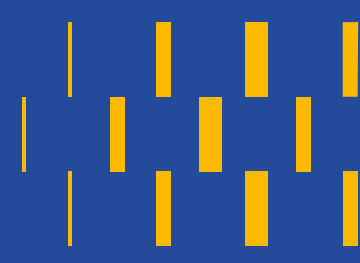

\title{
Pastores y agricultores de Socoroma: un caso de complementariedad ecológica durante el siglo XX en el extremo norte de Chile
}

\section{Shepherds and farmers of Socoroma: a case of ecological complementarity during the 20th century in northern Chile}

Jorge Moreira Peña ${ }^{1}$ (D) https://orcid.org/0000-0003-1122-6737

${ }^{1}$ Grupo de Estudio Transcultural del Parentesco (Getp-GRAFO), Departamento de Antropología Social y Cultural, Universidad Autónoma de Barcelona, Barcelona, ESPAÑA. Email: jorge.moreira.p@hotmail.com

\section{Resumen}

Se presentan los resultados de una investigación sobre complementariedad ecológica en una comunidad aymara localizada en la sierra de Huaylillas, región de Arica-Parinacota. A partir de un análisis histórico e información etnográfica, se estudió en perspectiva diacrónica la complementariedad ecológica desplegada por las familias de Socoroma con el objetivo de acceder a recursos presentes en diversas zonas productivas. La etnografía destaca que durante el siglo $\mathrm{XX}$ este sistema se caracterizó por un patrón de movilidad y residencia temporal que ligó el territorio tanto de manera intracomunal -entre las distintas localidades pobladas del espacio comunitario- como extracomunal -en desplazamientos hacia la costa, valles adyacentes y sectores altiplánicos-. Se propone que durante el siglo pasado esta forma de habitar e integrar el territorio descansó principalmente en las dinámicas pastoriles de la población, las que de acuerdo a distintos contextos históricos intensificaron y constriñeron los modos de complementariedad ecológica.

Palabras clave: complementariedad ecológica, movilidad, comunidad aymara. 


\begin{abstract}
These are the results of an investigation on ecological complementarity in an Aymara community located in the Sierra de Huaylillas, Arica-Parinacota Region. Based on historical research and ethnographic data, it was analysed in diachronic perspective the ecological complementarity displayed by Socoroma's families with aim of accessing to resources in multiples productive zones. The ethnography highlights that during the 20th century this system was characterized by a pattern of mobility and temporary residence linking the territory both intra-communal -between the different populated localities of the community space- and extra-communal -in displacements towards the coast, adjacent valleys and highlands-. It is proposed that during the last century this way of inhabiting and integrating the territory rested mainly on pastoral dynamics, which intensified and constrained the modes of ecological complementarity according to different historical contexts.
\end{abstract}

Keywords: ecological complementarity, mobility, aymara community.

Recibido: 19 mayo 2020. Aceptado: 31 agosto 2020 


\section{Introducción}

Conversando con los antiguos ${ }^{1}$ de Socoroma, es común escuchar historias de viajes, de largos caminos guiando los animales, de paisajes cambiantes, de días enteros pastoreando en los cerros, de productos traídos desde los valles. Aquellos viajes que unían el territorio, las motivaciones y las relaciones sociales que anudaban esos movimientos son el foco de este artículo. El interés por comprender esta movilidad desde una perspectiva diacrónica condujo a darle sustento teórico en los sistemas de complementariedad ecológica que se han estudiado en los Andes. Según registros históricos, esta forma de concebir el territorio es posible remontarla hasta tiempos precolombinos, siendo incluso entendida como un "ideal cultural" de las poblaciones andinas en función del aprovechamiento de los recursos disponibles en el medio ambiente (Murra, 1975; Salomon, 1985).

En Socoroma todavía eran visibles estas prácticas territoriales durante la segunda mitad del siglo XX, perdiendo paulatinamente su vigencia a partir de la década del setenta, asociadas a diversos cambios tecnológicos y socioculturales en el contexto regional. En efecto, al momento de la etnografía (ańos 2015-2016) aquellas historias solo se revivían en la memoria de los socoromeños, mientras en los caminos el paso del tiempo borraba sus pisadas. Lo que aquí se presenta es, por tanto, una etnografía del pasado, al focalizar la atención sobre movimientos que dejaron de realizarse algunas décadas atrás, antes de finalizar el siglo XX; aunque de un pasado cercano, que todavía era posible recuperar etnográficamente a través de conversaciones con los miembros de la comunidad, recopilando narraciones sobre una forma local de habitar el territorio.

Analizar recientes sistemas de complementariedad ecológica en la región tiene importancia porque el tema ha sido revisado principalmente a través de investigaciones arqueológicas y etnohistóricas, obteniendo menor atención desde estudios etnográficos, con excepción de los trabajos de Castro y Bahamondes (1987, 1988) en Lluta, y de Platt (1975) en Azapa. Las etnografías locales se han centrado mayormente en procesos de migración campo-ciudad ocurridos en la segunda mitad del siglo XX, aunque se constata un creciente interés por diversos aspectos relacionados con la movilidad de las poblaciones andinas contemporáneas (García y Ajata, 2016; Méndez-Quiróz y García, 2018; Cerna y Muñoz, 2019). En particular, esta etnografía contribuye a comprender la contextualización de los sistemas de complementariedad desde una comunidad aymara, los cambios y continuidades en sus formas de habitar el territorio y el esfuerzo puesto en crear y mantener diversos tipos de interacciones sociales, especialmente durante el siglo pasado que trajo consigo importantes transformaciones globales en la región estudiada.

El análisis enfatiza la importancia que tuvo la ganadería en el despliegue de la complementariedad ecológica desarrollada por una comunidad precordillerana, teniendo en cuenta que generalmente las poblaciones serranas han sido caracterizadas como agricultoras debido a sus evidentes obras de canalización y regadío, relegando a un segundo plano la actividad pastoril, camélida en tiempos precolombinos y fundamentalmente ovina desde la Colonia, adaptación eficiente que realizaron las poblaciones indígenas y que contribuyó a modelar una forma de vida en constante movilidad.

En cuanto a los aspectos metodológicos, es una investigación cualitativa con una etnografía multilocal (Marcus, 2001). Si bien el punto de partida ha sido Socoroma, según la pertinencia

1 Nombre con que se denomina a las personas más longevas de la comunidad. 
el estudio se ha realizado en distintos espacios de interacción. Metodológicamente, esto ha permitido conjugar una multiplicidad de visiones que se han generado en las distintas localidades debido a las dinámicas de la complementariedad ecológica en la región. La información etnográfica se obtuvo mediante trabajos de campo realizados específicamente durante los meses de octubre-noviembre del 2015, enero-febrero y mayo del 2016; se efectuaron entrevistas semiestructuradas y en profundidad a miembros de las cinco localidades pobladas, a personas que mantienen relaciones en sectores hoy considerados fuera del territorio comunitario pero que antiguamente funcionaban como lugares de residencia temporal (Sora y Arancha en el valle de Lluta), y a socoromeños que actualmente viven la mayor parte del ańo en Arica. El universo de entrevistados corresponde a 25 personas, quienes se seleccionaron con base en dos criterios fundamentales: factor etario y experiencial. La mayoría de los entrevistados se encontraba entre los 60 y 90 años, posibilitando extender la memoria histórica hasta comienzos del siglo XX; se privilegiaron relatos de quienes vivieron tiempos prolongados en el territorio, habiendo conocido personalmente o mediante narraciones de sus antepasados los desplazamientos descritos. El interés general estuvo puesto en las experiencias en torno al trabajo agrícola, al pastoreo y los intercambios, en la medida que permiten comprender la movilidad permanente que practicaron durante el siglo XX. De este modo, la etnografía ha sido el método de investigación sociocultural para conocer la intersubjetividad de los procesos de complementariedad desarrollada por los pastores y agricultores de Socoroma, la que pretende valorizar sus voces, sus memorias, motivo por el cual es presentada mediante sus descripciones.

El texto se estructura en cinco secciones; primero, se presenta sintéticamente la comunidad y el medio ambiente; segundo, se reseña el desarrollo inicial de la idea de complementariedad ecológica entendida a partir de distintas disciplinas y perspectivas; tercero, se realiza un análisis diacrónico de esta modalidad específicamente para el sector de Socoroma, desde sus primeros registros arqueológicos hasta el siglo XX; cuarto, se analiza el caso etnográfico de complementariedad practicado por los socoromeños durante el siglo pasado; quinto, se esbozan algunas conclusiones con aspectos relevantes de los resultados.

\section{Ecología y comunidad}

El territorio de Socoroma forma parte del área centro-sur andina, conceptualización que si bien proviene de la arqueología y se relaciona con las tecnologías utilizadas por las poblaciones que habitaron esta zona, es pertinente entenderla como marco geográfico, porque muestra la presencia de características comunes y a la vez diversas, gracias a prolongados contactos interétnicos en el tiempo. Esta área comprende el sur del Perú y norte de Chile, desde el río Majes en Arequipa hasta el río Salado en Antofagasta, abarcando la costa y los Valles Occidentales, los territorios que rodean al lago Titicaca, el altiplano meridional entre Bolivia, Argentina y Chile, y la zona circumpuneña de Atacama (Núñez y Dillehay, 1995 [1979]; Hidalgo, Schiappacasse, Niemeyer, Aldunate y Solimano (Eds.), 1997 [1989]).

Específicamente la comunidad se localiza en la cabecera del valle de Lluta, sector comprendido en los Valles Occidentales de los Andes. Desde el punto de vista orográfico, el relieve presenta una amplia diversidad de ecosistemas de acuerdo a las gradientes altitudinales que exhibe el territorio, evidenciándose lo que Núńez y Dillehay (1995, p. 33) han considerado como una "impresionante zonificación vertical" debido a los pronunciados cambios de altitud en cortas distancias, siendo posible distinguir cuatro pisos ecológicos diferenciados: costa, valles, precordillera y altiplano. Los cambios altitudinales cumplen un rol fundamental en la variedad 
de climas y disponibilidad de recursos bióticos, diferencias ecosistémicas que han impelido la generación de estrategias adaptativas en las poblaciones andinas, con distintas formas de ocupación del espacio y explotación de los recursos, dando paso a la formulación de singulares sistemas de complementariedad ecológica.

En este contexto macroecológico, el territorio comunitario de Socoroma abarca alrededor de 37 241,52 ha. ${ }^{2}$ Se compone de cinco localidades pobladas ubicadas a una altura promedio de 3000 msnm y distribuidas en dos cuencas hidrográficas adyacentes: Lluta y Azapa. Existe gran diferencia de altitud entre la parte alta del territorio por el este y la baja al oeste, las quebradas descienden abruptamente hacia la costa permitiendo la generación de microclimas al interior del territorio, utilizados por los socoromeños para diversificar su producción agrícola. El clima de desierto marginal de altura se caracteriza por escasas precipitaciones anuales concentradas en los meses estivales, con una estación seca bastante prolongada.

Las cinco localidades que componen el territorio comunitario tienen por nombre Zapahuira, Murmuntani, Epispacha, Chusmiza y Socoroma, de las cuales solo la última es considerada como "pueblo" por sus habitantes; mientras el resto, como "caseríos". Estos asentamientos se encuentran vinculados por extendidas relaciones de parentesco, cuyos habitantes reconocen pertenecer a las mismas familias que componen la comunidad de Socoroma, ${ }^{3}$ aspecto que históricamente ha contribuido a dinamizar la complementariedad ecológica al interior del territorio.

Los residentes permanentes al momento de la etnografía fueron estimados en 60 individuos en alrededor de 30 unidades domésticas, aproximadamente la mitad residiendo en Socoroma mientras la otra está distribuida heterogéneamente en el resto de los asentamientos, si bien cabe destacar que la cantidad de habitantes varía notoriamente durante el año en relación al ciclo agrícola. En tiempos de siembra y cosecha, y cuando la temperatura es benigna para los adultos mayores, aumenta la población estable durante varias semanas, alcanzando un número superior a las 100 personas. A pesar de este movimiento oscilante, concordante con los procesos demográficos ocurridos a nivel regional, se evidencia una tendencia a la disminución de residentes permanentes en todo el territorio comunitario. En términos de adscripción étnica, casi la totalidad de la población se considera perteneciente al pueblo aymara.

Respecto a las actividades productivas, la mayoría de las personas se dedican a la agricultura, cultivando fundamentalmente maíz, papas y orégano, los primeros destinados al consumo familiar mientras que el último a comercialización en el mercado. Debido a la escasez de agua se han construido extensas andenerías y obras de canalización para el riego de los cultivos, muchas de las cuales tienen origen prehispánico (Santoro, Hidalgo y Osorio, 1987). La ganadería, actividad presente desde tiempos precoloniales (Saintenoy, Ajata, Romero y Sepúlveda, 2017), y que era tan importante como la agricultura solo unas décadas atrás, ha experimentado un decaimiento sostenido desde los setenta. Los años 2015-2016 las unidades domésticas que mantenían rebaños - de tamaños relativamente discretos-, no alcanzaban la media decena. En los últimos ańos algunas familias han incursionado en negocios relacionados con el turismo

2 El territorio comunitario tiene la categoría de propiedad fiscal en virtud de las inscripciones globales realizadas por el Conservador de Bienes Raíces de Chile en 1935. Actualmente, mediante un proyecto convenio entre CONADI y la Gobernación de Arica y Parinacota, este se encuentra en proceso de regularización para ser inscrito a nombre de las comunidades indígenas que lo conforman.

3 En adelante cuando se hable de la comunidad de Socoroma se estará aludiendo a todas las localidades que forman parte del territorio comunitario (Zapahuira, Murmuntani, Epispacha, Chusmiza y Socoroma). 
rural, estimulados por la disponibilidad de recursos públicos y privados, aunque todavía es una actividad incipiente. De estas tres actividades, la agricultura es la que hoy tiene mayor relevancia para las familias socoromeñas.

Una característica general de las comunidades indígenas del norte de Chile es actualmente su carácter translocal, en el sentido de que su realización colectiva trasciende el espacio comunitario, complejizando sus relaciones y diversificando el tipo de actividades económicas, sociales y políticas en toda la región (Gundermann, 2001; Gundermann y Vergara, 2009; González, Gundermann e Hidalgo, 2014). A la par con esta translocalización ha ocurrido un proceso de fragmentación comunitaria, las localidades han adquirido mayor autonomía respecto a la importancia que presentaba el pueblo como centro cívico y religioso de la comunidad, fundamentalmente como resultado de las políticas de reconocimiento hacia los pueblos originarios promovida por el Estado chileno a inicios de los ańos noventa que legitimaron la formación de "comunidades indígenas" a partir de pequeñas unidades sociales, ${ }^{4}$ aunque también debido a factores internos. Para el caso de Socoroma, solo la localidad de Epispacha no ha constituido una comunidad indígena de manera autónoma. A pesar de esta fragmentación, por el momento, entre sus miembros no es cuestionada la pertenencia histórica de las localidades al pueblo de Socoroma como entidad integradora del territorio comunitario.

\section{Hacia la idea de complementariedad ecológica}

Durante la primera mitad del siglo XX las poblaciones de los Andes habían sido estudiadas por la antropología social desde las ideas del culturalismo y funcionalismo, pero en la década del sesenta se nutrió de la corriente de ecología cultural que ponía énfasis en los procesos de mutuos ajustes entre las poblaciones humanas y su medio geográfico, en "la adaptación de instituciones sociales a los requerimientos ecológicos, o, viceversa, la modificación humana del medio ambiente para adecuar este a los requisitos que la sociedad impone" (Mayer, 1994, p. 481). Si bien John Murra no explicitó que siguiera esta corriente, en sus trabajos etnohistóricos sobre las sociedades prehispánicas del Perú analizó la relación particular de sus habitantes con la geografía, destacando la importancia del factor ecológico para entender el desarrollo de las sociedades andinas, señalando que "[1]a percepción y el conocimiento que el hombre andino adquirió de sus múltiples ambientes naturales a través de milenios le permitió combinar tal increíble variedad en un solo macro-sistema económico" (Murra, 1975, p. 59), sistema que conceptualizó como el control vertical de un máximo de pisos ecológicos. Algunos autores vislumbraron con anterioridad la idea de utilización simultánea de distintas ecologías, como el caso de Carl Troll (1987 [1958]) o Ramiro Condarco (1987 [1971]), pero se debe a Murra el análisis y sistematización de la información disponible, tanto en crónicas como documentos administrativos coloniales, para mostrar los criterios utilizados por las poblaciones andinas en su interacción con la ecología y el consecuente control de los recursos. Abordando la dialéctica de continuidad y cambio referida al problema de obtención de los recursos, Murra se interesó especialmente en las permanencias frente a los cambios históricos. Para el autor lo que se mantenía era el "ideal andino" de autosuficiencia, el acceso de manera directa a zonas productivas diversas en virtud de las gradientes altitudinales que presenta el paisaje en los Andes, apuntando que "[g]randes o pequeños, los grupos étnicos tenían una percepción similar de los recursos y la manera de obtenerlos. El deseo de controlar zonas climáticas alejadas mediante colonos

4 La Ley 19.523 en su artículo $9^{\circ}$ permite formar Comunidades Indígenas a personas que "Provengan de un mismo tronco familiar" o que "Provengan de un mismo poblado antiguo", con al menos 10 miembros mayores de edad. 
permanentes, determinó un patrón de asentamiento y de control vertical cuya distribución fue probablemente panandina" (Murra, 1975, p. 50). Es decir, el archipiélago vertical tenía por objetivo alcanzar el autoabastecimiento de un grupo étnico que, basándose en los principios de reciprocidad y redistribución, lograba acceder a bienes suficientes y diversificados mediante la instalación de colonos en distintos pisos ecológicos, quienes no perdían los derechos en sus lugares de origen.

A partir de su propuesta se produjeron abundantes investigaciones arqueológicas, etnohistóricas y antropológicas referidas a la relación entre sociedad y ecología, demostrando que la variedad de recursos permitida por las diferencias altitudinales había estimulado la generación de estos sistemas macroadaptativos. Y si bien el concepto inicial introducido por Murra fue el de control vertical, las consiguientes investigaciones comenzaron a establecer relaciones funcionales entre esta verticalidad y otras dimensiones de la vida social de las poblaciones andinas, produciéndose una extensión en la complejidad y diversidad del sistema que amplió el concepto hacia la idea de complementariedad ecológica. Debido al extenso volumen de estudios referidos al tema, a continuación se destacan solamente las propuestas pioneras y aquellas que tuvieron relevancia teórica.

Desde la etnografía, fueron significativos los trabajos llevados a cabo en comunidades quechuas del Perú que contribuyeron al conocimiento de la aplicabilidad del sistema en tiempos contemporáneos. Steven Webster (1971) evidenció que el funcionamiento de la complementariedad en el distrito de Marcapata era practicado a nivel de las unidades domésticas y no se encontraba reglamentado comunitariamente. Stephen Brush (1987 [1974]) mostró distintas variantes de la verticalidad en la comunidad de Uchumarca, con la existencia de diversos tipos de relaciones ecológicas: del tipo compacto, archipelágico y extendido. Las prolongadas etnografías producidas por Enrique Mayer y César Fonseca (1988) en la quebrada de Chaupiwaranga en Huánuco y las dirigidas por Shozo Masuda (1981) en los Andes meridionales comprobaron la vigencia de las relaciones verticales, a la vez que mostraron sus transformaciones producto de variaciones geográficas y procesos históricos particulares.

Algunos antropólogos se preocuparon por las vinculaciones existentes entre la economía vertical y relaciones de parentesco, como fue el caso en Bolivia de Tristan Platt (1980 [1971]) y Olivia Harris (1978). En el estudio sobre el ayllu Macha, Platt centró la atención en la lógica binaria del sistema simbólico de las sociedades andinas para entender la relevancia de la organización vertical del espacio. Por su parte, Harris analizó en el ayllu Laymi cómo el control vertical de pisos ecológicos determinaba la organización social del grupo, considerando la importancia de las relaciones de parentesco en la tenencia de la tierra, el acceso a mano de obra y los intercambios productivos, e introduciendo el concepto de doble domicilio para describir el funcionamiento de las familias que explotaban simultáneamente distintos pisos ecológicos.

Otros investigadores se enfocaron en la relación del control vertical con los ciclos agropecuarios. Jurgen Gölte (1980), evidenciando las condiciones de baja productividad en los Andes peruanos, señaló que durante milenos las poblaciones andinas debieron crear formas organizativas que hicieran posible la vida ante esta desventaja impuesta por la geografía, lográndolo gracias a la movilización y utilización eficiente de la fuerza de trabajo, mediante el manejo paralelo de ciclos agrícolas como forma de aprovechar la diversidad de pisos ecológicos. Gölte reafirmó sus ideas con Marisol de la Cadena (1986), agregando que todo análisis debe integrar el factor mercado por el fuerte impacto que ha tenido en las comunidades campesinas, sobre todo durante el siglo XX. Alejandro Camino (1982) siguió un rumbo similar al de Gölte en el sentido de 
entender los Andes como un espacio de producción inestable que requiere una adecuada coordinación humana; considerando la importancia que tuvo la calendarización de las actividades agrícolas para los incas y observando procesos de sincretismos provocados por la colonización castellana, vinculó la idea de temporalidad de Earls a la de verticalidad propuesta por Murra para analizar calendarización de las festividades religiosas en la planificación de las actividades agrícolas en el distrito de Cuyo-Cuyo en Puno, concluyendo que cada familia establecía un ciclo agrícola propio con el objetivo de utilizar simultáneamente diferentes zonas ecológicas.

Desde la etnohistoria, por supuesto, se realizaron importantes contribuciones. Udo Oberem (1981 [1976]), analizando las sociedades indígenas de la sierra ecuatoriana del siglo XVI planteó la existencia de una microverticalidad, por oposición a la macroverticalidad destacada por Murra. Su propuesta se distinguió por la ausencia de colonias residentes en los sectores productivos, ya que los pueblos tendrían cultivos en distintos pisos ecológicos alcanzables en un viaje relativamente acotado, pudiendo regresar al lugar de origen dentro de una misma jornada. Idea similar a la de Brush referente al archipiélago compacto, con la diferencia que Oberem se refiere a sociedades del siglo XVI y Brush a contemporáneas. Por su parte, María Rostworowski (1977) puso a prueba los postulados de Murra, seńalando que en la zona costera del Perú operaría otro sistema económico diferente a la verticalidad de la sierra, con características de especialización laboral por oficios, destacando pescadores y gran cantidad de artesanos, lo que habría dado paso a un variado y extenso intercambio de productos longitudinalmente a través del mar. Al no existir un control directo, Rostworowski no solo descartó la aplicación de la idea propuesta por Murra, sino que además abrió la posibilidad de pensar la complementariedad a partir de interacciones horizontales.

Desde la arqueología, continuando con algunos planteamientos de Rostworowski, Izumi Shimada (1982) propuso un modelo de archipiélago horizontal para las poblaciones de los valles costeros septentrionales del Perú, en la región de Lambayeque, enfatizando las relaciones intervalles, las que serían utilizadas por un mismo grupo étnico manteniendo un amplio sistema de intercambio, tanto de manera vertical como entre los valles adyacentes dispuestos longitudinalmente. Por otra parte, como alternativa al modelo de archipiélago, David Browman (1980) propuso el altiplano mode para una fase del desarrollo de Tiawanaku; considerando las características específicas del altiplano boliviano, distinguió un tipo de integración económica basada en el acceso a recursos de otras zonas ecológicas mediante especialización productiva, ferias y redes de intercambio conectadas por tráfico caravanero. Una mirada más integradora fue propuesta por Lautaro Núñez y Tom Dillehay (1995) con el modelo movimiento giratorio; analizando diacrónicamente la movilización de recursos practicada por los pastores de la puna en múltiples espacios, consideraron la trashumancia, la verticalidad y la complementariedad ecológica como aspectos dentro de patrones más integradores de movilidad andina, los que permitirían explicar el desarrollo cultural de los Andes centro-sur.

Una síntesis y evaluación a partir de las investigaciones realizadas hasta el momento fue presentada por Frank Salomon, ofreciendo una tipología de los diversos mecanismos de complementariedad (multifariuos complementary) y un análisis de la complementariedad vista en perspectiva diacrónica (changing complementary), señalando que estos pueden clasificarse dentro de algunos patrones que se repiten en distintos lugares y momentos del contexto andino (Salomon, 1985, pp. 511-512). Destacó especialmente el dinamismo de los sistemas de complementariedad ecológica, ya que, a pesar de las transformaciones experimentadas en distintos contextos históricos, estos han tenido la capacidad de mantenerse en el tiempo como forma de subsistencia de las poblaciones andinas. 
Esta diversidad de investigaciones profundizó y planteó nuevas perspectivas a la idea fundamental de Murra, constituyéndose en referentes para comprender las relaciones entre sociedad y medio ambiente en los Andes, entregando pistas para analizar características del caso de Socoroma durante el siglo XX. De acuerdo a la trayectoria descrita, se aprecia que el término más adecuado para conceptualizar esta relación es complementariedad ecológica, ya que el control vertical de Murra en muchos casos resultaba un concepto que restringía las posibilidades de las interacciones, debiéndose entender como una respuesta inicial al problema de la subsistencia en los Andes, la que se iría enriqueciendo con el transcurso de las investigaciones. Así, complementariedad ecológica se dibujó como un concepto más flexible, que ha permitido entender la complejidad y diversidad de los persistentes fenómenos macroadaptativos en la región andina.

\section{Complementariedad ecológica en perspectiva diacrónica}

Los patrones de ocupación y movilidad desplegada por las poblaciones del área específica de la vertiente occidental de los Andes, donde se localiza Socoroma, ${ }^{5}$ han variado en referencia a contextos históricos y condiciones medioambientales cambiantes. Los permanentes ajustes adaptativos de los socoromeños han modificado constantemente su forma de habitar el territorio, aunque manteniendo presente la práctica de complementariedad ecológica, al menos hasta las últimas décadas del siglo XX, como demuestra esta investigación.

Esta área ha sido habitada al menos desde 12000 años (Dauelsberg, 1992-1993; Hidalgo et al., 1997 [1989]), tiempo en que el sector alto de Lluta habría funcionado como corredor que atravesaron cazadores-recolectores del período paleolítico en busca de recursos. Durante milenios los grupos humanos habrían practicado patrones de movilidad, desplazándose en amplios territorios e instalando campamentos estacionales de acuerdo con la disponibilidad de recursos según las estaciones del año, sin ejercer un dominio específico sobre el territorio, motivo por el cual para Núñez y Dillehay (1995, p. 55) el control vertical de diversos pisos ecológicos todavía no sería una expresión cultural de estos primeros pobladores.

El estadio agropecuario se desarrolló a partir del 2000 AC en las zonas costeras de los valles y en el altiplano, sin evidencias de que esto ocurriera en el sector precordillerano (Núñez, 1997, p. 81). Este lugar, no obstante, pudo ser utilizado como paradero por los grupos caravaneros movilizándose entre costa y altiplano. Según Mujica, Rivera y Lynch (1983), a partir de la expansión de Tiawanaku desde el sector circumpuneño hacia la vertiente occidental de los Andes, alrededor del 500 DC, se puede advertir la presencia de mecanismos de control vertical en la costa de Arica mediante la instalación de colonias pertenecientes a los grupos altiplánicos. Para Rivera (1975) el caso de Alto Ramírez en Azapa es posible remontarlo incluso a períodos anteriores, si bien es una hipótesis en discusión porque otros autores consideran que esta sociedad resultaría de una trasformación propia de los grupos locales costeros (Santoro, Romero, Standen y Torres, 2004). Berenguer y Dauelsberg (1997, p. 138) consideran que el mecanismo de verticalidad se encontraba presente durante la expansión de Tiawanaku, incorporando su área periférica mediante la instalación de colonias permanentes que permitían tener acceso directo a recursos distribuidos en los valles y la costa, como maíz, coca o ají, a la vez que posibilitaba la extensión del ciclo agrícola. Por su parte, para este período Llagostera (2010, p. 286) señala que en los Valles Occidentales no existiría un control directo de distintos pisos ecológicos por

5 La discusión se centra específicamente en los Valles Occidentales, en particular Lluta, por lo que no se ha considerado bibliografía referida a otras áreas, como por ejemplo Atacama, abundante en investigaciones arqueológicas, etnohistóricas y etnográficas. 
parte de una misma colectividad, sino que serían comunidades independientes practicando un fluido sistema de intercambio de bienes basado en principios de reciprocidad y redistribución, lo que ha llamado integración complementaria.

Con la decadencia de Tiawanaku, alrededor del 1000 DC, se produjo una inestabilidad generalizada en la macrozona, surgieron grupos étnicos independientes y en los sectores costeros se desarrolló una sociedad con características propias, la cultura Arica, formada por un segmento de pescadores o camanchaca y otro de agricultores o coles (Muñoz y Choque, 2013; Horta, 2015), período conocido localmente como Desarrollo Regional. Respecto a la situación política e identidad étnica de la población serrana del Colesuyu, se discuten varias hipótesis: fueron grupos locales dominados por los llamados "reinos altiplánicos" surgidos post-Tiawanaku (Lumbreras, 1974); pertenecieron al sector cole de la cultura Arica dirigidos desde la costa (Muńoz, 1997; Chacama, 2005; Muńoz y Choque, 2013); constituyeron grupos diferenciados de los costeros y altiplánicos, relativamente independientes, caracterizados por conformar aldeas agrícolas con complejos sistemas de andenerías y canalización para labores agrícolas, formando un tipo de identidad colectiva particular expresada en el estilo cerámico Charcollo (Romero, Santoro y Santos, 1998; Santoro et al., 2004), pero que además combinaron la agricultura con una importante actividad pastoril (Saintenoy et al., 2017); agruparon poblaciones yungas y colonias altiplánicas que mantuvieron alianzas de territorialidad compartida, conservando sus identidades étnicas (Horta, 2015). Entre los autores existe consenso, sin embargo, en la existencia multiétnica y que con el transcurso de los años, en el período previo a la expansión del Tawantinsuyu, los grupos altiplánicos habrían intensificado su presión sobre los sectores precordilleranos y costeros para acceder de manera más eficiente a productos diversificados, logrando establecer colonias en diversos tramos del valle de Lluta, si bien esto se produjo no solo mediante la verticalidad, sino ejerciendo diversos mecanismos de complementariedad (Santoro et al., 2010).

La expansión incaica habría utilizado las colonias altiplánicas para acceder a la zona, motivo por el que Llagostera $(1976,2010)$ ha planteado que el dominio inca en Lluta ocurrió de manera indirecta, hipótesis que ha sido corroborada por Horta (2015) solo para la cabecera del valle, pues la cultura Arica mantendría su autonomía en la costa. Para Núñez y Dillehay (1995, p. 130), el Estado inca conservó los sistemas de complementariedad ecológica prexistentes con el respectivo acceso a recursos distantes mediante colonias, pero interfiriendo la movilización de bienes hacia el Estado centralizado, por lo que, a pesar de esta importante transformación, en la región se habría mantenido un control vertical de los recursos dirigidos desde el altiplano. Sin embargo, con la expansión incaica los principios de reciprocidad y redistribución que sustentaban el modelo de Murra se encontraban en proceso de transformación. Watchtel (1973, p. 77), analizando las colonias especializadas incaicas y las establecidas a larga distancia, señala que las relaciones de parentesco de los colonos estaban en proceso de desvinculación y, con ello, perdiendo los derechos en sus comunidades de origen; la reciprocidad adquiriría solo una función ideológica que legitimaba el nuevo orden social impuesto por el Estado inca, con lo que el archipiélago vertical se estaba convirtiendo en uno de tipo estructural. El proceso de dominio inca y la consiguiente transformación de las relaciones fue relativamente breve en el área estudiada, truncado por la conquista y colonización hispana.

El sistema colonial reorganizó las actividades productivas en función de la minería. El descubrimiento del mineral de Potosí a mediados del siglo XVI modificó los destinos de la movilidad y el tipo de relaciones complementarias (Rivera, 1995-1996). El camino que conectó Arica con Potosí, conocido como Ruta de la Plata, tuvo una intensa utilización y debido a que atravesaba 
el territorio socoromeño, es probable que su población tempranamente se haya integrado a la arriería colonial, ya fuera como prestadores de servicios o directamente como arrieros (Choque y Muñoz, 2013). Las actividades de arriería y crianza de animales fueron muy importantes para la inserción de los socoromeños al sistema mercantil, aspecto que fue continuado durante tiempos republicanos (Hidalgo, Arévalo, Marsilli y Santoro, 1988; Ruz, 2008) hasta mediados del siglo XX. Por otra parte, en términos geopolíticos, el proceso colonial reconfiguró el territorio mediante la creación de nuevas unidades político-administrativas y especialmente con el establecimiento de las reducciones toledanas desde la década de 1570, provocando una ruptura de las lealtades étnicas y desintegrando los sistemas de complementariedad ecológica en distintas regiones (Murra, 1975; Saignes, 1991).

Para el caso de Arica y sus valles, considerando los planteamientos de Murra y revisando documentos administrativos del temprano período colonial, Durston e Hidalgo (1997) plantearon la existencia de un modelo prehispánico particular de complementariedad ecológica que denominaron verticalidad escalonada. El modelo considera la articulación de tres niveles políticos y productivos que se corresponden con determinados pisos ecológicos: los centros primarios serían los núcleos de máxima autoridad, desde donde los "mallkus" altiplánicos controlaban los archipiélagos de valle; un ejemplo correspondería al pueblo de Turco-Hatun Caranga. Los centros secundarios serían aldeas de considerable tamaño ubicadas en precordillera, de más de 100 individuos, cumpliendo funciones productivas, redistributivas y también de control sobre el valle, manteniendo los "caciques de valle" una relación directa con las autoridades del altiplano; concretamente uno de estos centros correspondería al pueblo de Socoroma. Por último, los centros terciarios serían poblados más pequeños, de entre 10 y 30 personas, organizados desde los pueblos precordilleranos con fines productivos; las autoridades llamadas "principales" se encontrarían supeditadas a los "caciques de valle" y a través de ellos, de manera indirecta, a los "mallkus altiplánicos"; en Lluta uno de estos centros lo constituiría Sora. En este esquema Socoroma es un nivel intermedio de control entre el centro principal y las colonias más alejadas, con autoridades y un sistema organizativo propio. Para los autores, este tipo de complementariedad constituiría un caso de verticalidad escalonada en el sentido que "implica el desdoblamiento de todas las estructuras verticales: la relación entre centro primario y centro secundario es reproducida en la relación entre centro secundario y centro terciario. Las colonias son ellas mismas generadoras de relaciones de verticalidad, estableciéndose como centros en relación a otras colonias" (Durston e Hidalgo, 1997, p. 255). Esta relación de dependencia entre TurcoHatun Caranga en el altiplano y Socoroma en la precordillera fue cortada estratégicamente por las autoridades indígenas con el amparo de los encomenderos espańoles, beneficiándose ambas facciones al utilizar las nuevas jurisdicciones coloniales para desligar a la población indígena precordillerana que había quedado sujeta a la mita de Potosí (Durston e Hidalgo, 1997, p. 260). Cabe señalar que, si bien se desarticuló el control directo ejercido por las poblaciones altiplánicas sobre las precordilleranas, los flujos demográficos y las relaciones socioeconómicas se mantuvieron vigentes durante el régimen colonial entre estos dos pisos ecológicos (Hidalgo y Durston, 2004 [1998]).

Un siglo más tarde, a mediados del XVII, las autoridades coloniales crearon el Cacicazgo de Codpa para retomar el control sobre la población precordillerana, lo que modificó las estructuras sociales y políticas de la región. Según Durston e Hidalgo (1997), esto dio paso a la regeneración de archipiélagos verticales en la relación precordillera-valle, estableciéndose los pueblos serranos como nuevos núcleos que ejercieron derechos sobre las tierras de los valles. Para los autores, el sistema de control vertical que puede apreciarse en el siglo XVIII en Lluta correspondería a nuevos archipiélagos, aprovechando la situación política en la que se encontraba la 
región (Durston e Hidalgo, 1997, p. 268). Específicamente, para el caso de Socoroma, desde la precordillera se volvió a establecer una ocupación del territorio a manera de islas productivas a lo largo del valle, modalidad que se había fracturado con el inicio de las imposiciones coloniales. Desde los pueblos serranos se tornó más importante la relación con los sectores de valle en sus tramos alto y medio, buscando concretar la independencia respecto de las poblaciones altiplánicas que pretendían el retorno de los colonos Caranga. Es probable que las estructuras archipelágicas situadas en el valle y la redistribución de la producción fueran controladas por las autoridades serranas, pues en este período se ha constatado una organización social jerarquizada en los pueblos precordilleranos (Inostroza, 2011). Xochitl Inostroza, revisando antecedentes parroquiales y censales de Socoroma en los tramos alto y medio del valle durante la segunda mitad del siglo XVIII, ha corroborado esta verticalidad escalonada, concluyendo que "[e]stos datos hacen evidente la naturaleza de Sora y Churińa, como 'islas' de pueblos como Socoroma” (Inostroza, 2010, p. 131).

Es interesante que incluso después de la independencia del Perú, en las primeras décadas del siglo XIX, y tras los cambios liberales que modificaron la relación de las comunidades con el Estado -desconocimiento de su estatus legal como entes corporativos, reducción de atribuciones de las autoridades locales, fragmentación de la tierra en unidades domésticas-, familias socoromeñas mantuvieron patrones de ocupación territorial con base en un control directo de la producción en sectores del valle, como exhibe en 1838 un documento de transacción de tierras en Churiña, cuyos propietarios eran indígenas de Socoroma (Hidalgo et al., 1988, p. 122). Es probable que los cambios introducidos por los gobiernos republicanos provocaran que hacia fines del siglo XIX el acceso de Socoroma a las tierras de Lluta ya no dependiera del control de las autoridades comunales, como ocurriría durante el período colonial según plantean Durston e Hidalgo (1997, p. 267), sino que descansara en la mantención de relaciones de parentesco ejercidas particularmente por unidades familiares. En este nuevo escenario es pertinente pensar que solo algunas familias continuaron ejerciendo derechos sobre sectores como Sora y Churiña, constituyendo un archipiélago vertical con características descentralizadas.

A fines del XIX se produjo la guerra que enfrentó a los Estados de Chile, Perú y Bolivia (18791883) por recursos salitreros de la zona. Tras su término la población de Arica y Tacna quedó bajo tutela de las autoridades chilenas mientras se esperaba la realización del plebiscito para decidir el futuro de esos territorios, lo que no llegó a efectuarse y condujo a una prolongada ocupación por parte del Estado chileno. Durante este período ocurrió un cambio significativo en la organización del territorio, estableciéndose una nueva forma de administración a través de la creación de subdelegaciones y distritos, uno de los cuales fue el distrito de Socoroma que incluyó las localidades de Zapahuira, Murmuntani, Chusmiza y Epispacha. A su vez, extensos sectores de pastizales de las comunidades fueron considerados fiscales, requiriendo permiso de las autoridades gubernamentales para su uso y limitando así el desplazamiento a las zonas habituales de pastoreo (Ruz, 2008). La movilidad de los socoromeños para ejercer la complementariedad, no obstante, se mantuvo dadas sus necesidades productivas. Otro cambio gravitante se produjo por la construcción del ferrocarril Arica-La Paz a comienzos del siglo XX. La instalación de estaciones ferroviarias en distintos sectores del territorio afectó la dirección de los desplazamientos y las relaciones de complementariedad. La estación Púquios, distante de Socoroma unas 12 horas en animal, se convirtió en foco de atracción para comercializar productos agropecuarios y abrió una nueva vía para alcanzar la ciudad de Arica sin recorrer el valle de Lluta, mientras que en los tramos bajos del valle las estaciones Rosario y Central 
también generaban demanda de productos. ${ }^{6}$ Terminado el período de ocupación y asegurada la soberanía del Estado chileno en Arica, a inicios de 1930 se flexibilizó el control y restricciones a los desplazamientos de la población, conduciendo a retomar algunas rutas y relaciones entre las localidades que se habían interrumpido solo parcialmente.

Esta anexión del territorio coincidió con los efectos de la crisis económica de los años treinta, provocando un estancamiento en la región hasta mediados de siglo, cuando el Estado chileno inició un proceso modernizador promoviendo planes de desarrollo para la zona norte centrados especialmente en las ciudades costeras. Arica experimentó un auge económico que dinamizó el conjunto de la región, incorporando tangencialmente los sectores rurales integrados a la red de comercio mediante sus productos agropecuarios, entre los que destacó el ganado debido a la demanda alimentaria que generaba la urbe en expansión. En 1953 se decretó el Puerto Libre, que liberó los derechos aduaneros de importación y exportación de mercancías, y en 1958 se creó la Junta de Adelanto de Arica, que comenzó a ejecutar importantes obras de infraestructura en la ciudad y las zonas rurales. Una de ellas fue la construcción del tramo de la Ruta 5 (Carretera Panamericana) que conectó Arica con el sur del país, cuya importancia para este estudio radica en que arribaron productos habitualmente proporcionados por los pueblos precordilleranos, especialmente carne, la que comenzó a ser abastecida mediante frigoríficos, provocando una disminución en la demanda de vacunos y ovinos ofrecidos por los sectores serranos. A su vez, se inició la construcción de la Ruta 11-CH (Carretera Internacional) que a fines de los años sesenta conectó mediante una red vial los pueblos altiplánicos y precordilleranos con Arica (Ruz, Galdames y Díaz, 2010), provocando una disminución de la movilidad mediante el tráfico arriero. Fue en esta década cuando se intensificaron los viajes de los socoromeños hacia la urbe costera, asentándose de manera relativamente estable estimulados por las oportunidades laborales y el acceso a servicios como salud y educación. La migración socoromeña más significativa de su historia se registró en este período: de 253 habitantes que tenía la comunidad en 1960 pasó a 127 en 1970, es decir, en tan solo una década disminuyeron un $50 \%$ los residentes permanentes. ${ }^{7}$ Este flujo demográfico tuvo consecuencias tanto en el patrón de ocupación del territorio comunitario como en la distribución de la población a nivel regional. En Socoroma, al disminuir la disponibilidad de fuerza de trabajo para las tareas agrícolas, se experimentó una reducción de la superficie cultivada, especialmente en los sectores más lejanos de los centros habitacionales; a su vez, al migrar a la ciudad numerosas familias vendieron parte o la totalidad del ganado, provocando una paulatina constricción de la movilidad, tanto por la disminución en la intensidad del uso de los sectores de pastoreo como de las rutas que unían las distintas localidades y a estas con el valle de Lluta. Por otra parte, en términos globales, trajo como consecuencia la regionalización de la sociedad aymara en vista de la ampliación y extensión del área de acción de la población indígena.

En la actualidad la mayoría de los socoromeños no reside en el territorio comunitario, se han establecido en distintos puntos de la región. Esto ha producido nuevas formas de concebir el territorio, proceso común entre las comunidades indígenas de la zona norte de Chile y que ha sido conceptualizado por Gundermann (2001) y González, Gundermann e Hidalgo (2014) como translocalización de las comunidades. Para los autores, la presente situación no constituiría una reedición de la complementariedad en distintos espacios ecológicos, sino que sería

6 Cabe aclarar que a través de la etnografía solo fue posible conocer el tipo de transformaciones ocurridas, no así su intensidad.

7 XIII Censo Nacional de Población y II de Vivienda, 1960, INE, Chile; XIV Censo Nacional de Población y III de Vivienda, 1970, INE, Chile. 
un fenómeno con dinámicas propias que lo distinguiría como un nuevo proceso histórico de las poblaciones andinas, al señalar que "el panorama parece ser más complejo que el de la posible continuidad de un ideal andino, ya que no se trata exclusivamente de la apropiación de diversos espacios de producción agropecuaria, sino de la realización de distintas actividades económicas agrarias y no agrarias y, en definitiva, de otra construcción histórica” (González, Gundermann e Hidalgo, 2014, p. 241).

\section{Complementariedad ecológica durante el siglo XX: el caso etnográfico de Socoroma}

El territorio donde se localiza Socoroma ha presentado una continuidad de ocupación durante milenios, cuyas poblaciones han ido transformando sus sistemas socioeconómicos en función de adaptaciones a contextos históricos cambiantes. En la estructuración de la complementariedad ecológica ha sido fundamental la función de las actividades económicas, en este caso agrícolas y pastoriles, así como también las formas de intercambio e inserción en el mercado. El desarrollo de estas actividades ha generado una forma particular de vida en constante movilidad, ejerciendo una territorialidad mediante desplazamientos y residencia temporal basada en la disposición de recursos.

Desde un punto de vista económico, la conjunción de dos factores principales ha estimulado la movilidad de los socoromeños en su búsqueda de una mayor amplitud y diversificación de recursos. En primer lugar, relativo a la agricultura, factores como la escasez de agua y salobridad de los terrenos han limitado la productividad, impulsando la ampliación de la superficie cultivable mediante la ocupación de distintos sectores altitudinales, evidenciado en las construcciones de extensas andenerías que alcanzan los lugares más bajos de las quebradas a manera de pequeñas parcelas productivas; la baja calidad en nutrientes de los suelos ha obligado a dejarlos en barbecho, estimulando también la búsqueda de nuevos lugares de cultivo cada vez más distantes de los núcleos poblados. En segundo lugar, sobre la actividad pastoril, la crianza de ganado que cada familia realizaba en considerables cantidades impelía un constante desplazamiento hacia lugares donde mantenían cultivos de alfalfa y hacia sectores de pastales en los cerros comunitarios.

En referencia al último punto, el piso precordillerano ha sido un espacio propicio para la práctica ganadera debido a su amplitud, cuenta con cursos regulares de agua y presenta una estación lluviosa que facilita el crecimiento de fuentes de alimentación (Muñoz et al., 1987; Santoro et al., 1987). La frase de la Sra. J. G., "Harto cordero habia antes, todas las familias sabian tener hartos corderos", ratificada por todas las personas entrevistadas, permite entender la existencia de una presión ganadera sobre el territorio, el que era utilizado extensivamente para obtener recursos forrajeros. Así, en función del ganado que poseían las familias socoromeñas se fueron estableciendo patrones específicos de movilidad y complementariedad ecológica de tipo local y regional.

En tiempos precolombinos la población serrana posiblemente centró su economía en la actividad agrícola, complementada con ganadería camélida, pero con la eficaz adaptación del ganado europeo que realizaron las sociedades indígenas durante el período colonial (ovino, vacuno y equino) se fue modificando su forma de ocupar el territorio. Si bien se mantuvo la estructura económica basada en la verticalidad, adquirió mayor importancia el desplazamiento al interior del territorio comunitario entre las localidades pobladas del sector serrano, estableciendo 
patrones de movilidad apreciables hasta la segunda mitad del siglo XX. Aunque con menor intensidad que los movimientos en la precordillera, los desplazamientos desde esta a los otros pisos ecológicos se mantuvieron vigentes, haciendo uso especialmente del valle de Lluta con el fin de ampliar las zonas productivas, tanto para la economía agrícola de subsistencia como para maximizar los recursos destinados a la reproducción de la actividad pastoril (Figura 1).

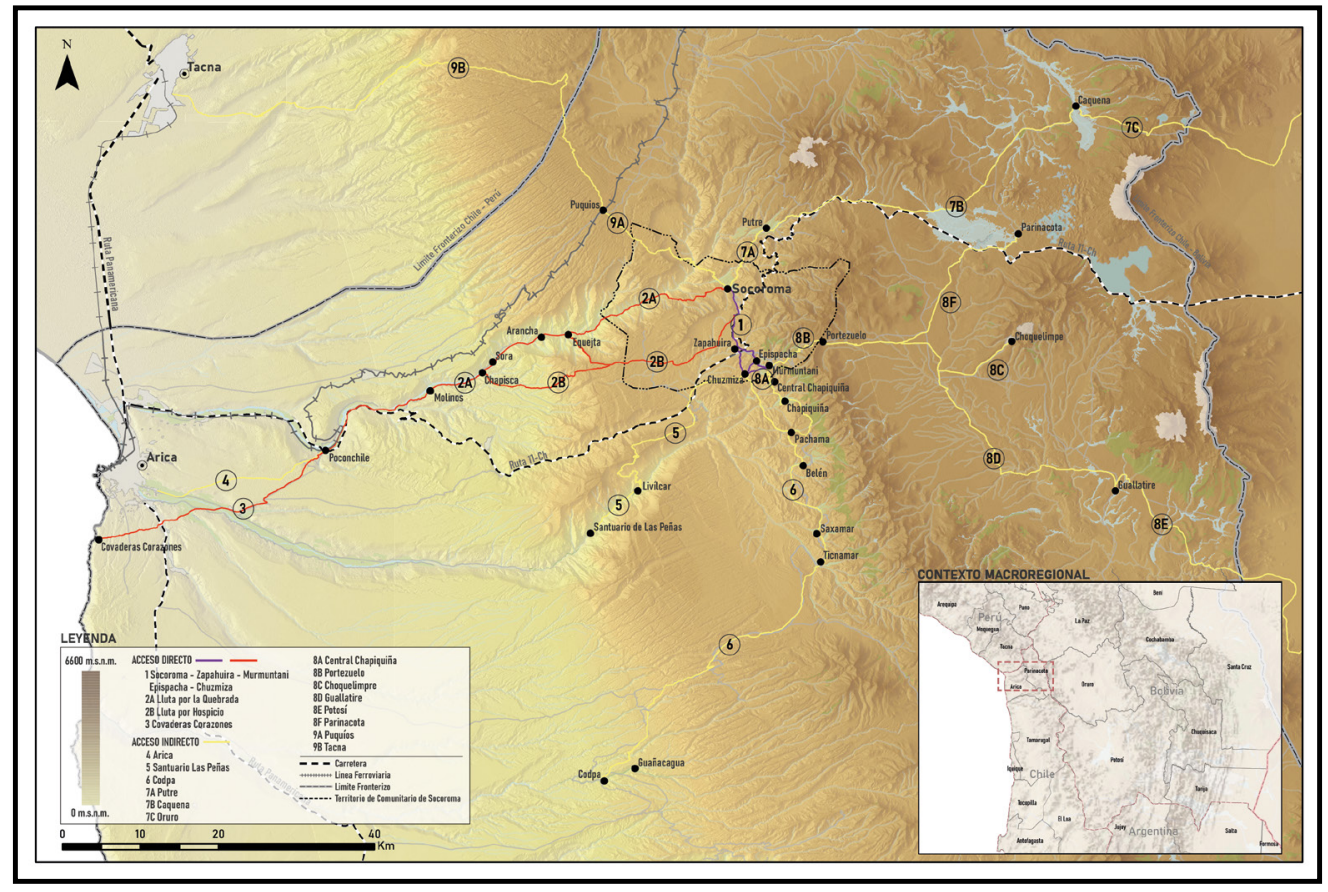

Figura 1. Movilidad territorial y complementariedad ecológica. Socoroma.

Acceso Directo. Este modo de complementariedad implicaba una participación directa de los socoromeńos en la producción de los bienes mediante desplazamientos tanto al interior del territorio comunitario como a sectores que excedían sus límites en diversas zonas productivas. Durante el siglo XX se constataron tres tipos de acceso directo: entre las localidades del territorio comunitario, entre estas localidades con el valle de Lluta, y en la extracción de guano en las covaderas. Las dos primeras ejerciendo control sobre las tierras, mientras que la tercera accediendo a terrenos fiscales.

Entre las localidades del territorio comunitario. Esta movilidad adquirió diversas formas considerando requerimientos económicos de las familias y su concreción según los derechos de acceso a la tierra y relaciones de parentesco mantenidas al interior de la comunidad. Existía un lugar central donde las familias vivían mayormente y utilizaban uno o varios domicilios en otros poblados con fines productivos, presentándose incluso casos que alternaban hasta cuatro residencias durante un mismo año:

Muchas familias de Socoroma tenian terrenos en Socoroma, Zapahuira y Murmuntani. Por ejemplo los H. tenian terreno en Socoroma, Zapahuira y Murmuntani y en Epispacha incluso. Entonces por eso estaba enrolado toda esa parte. Los B. igual, en Socoroma y en Murmuntani, aunque en Zapahuira no tenían. Los Q., también 
tenian en Socoroma y en Epispacha y Murmuntani. Entonces asi tenian varios. Mi papá era de las dos partes, porque tenía terreno en Zapahuira y Socoroma. Mi mamá estaba más en Socoroma (R.C.).

De acuerdo a los socoromeños, esto tiene su fundamento en la baja productividad del terreno que impelía a manejar ciclos paralelos de cultivos, pero sobre todo en las necesidades forrajeras del ganado. Al escasear el forraje, tras algunos meses alimentando el ganado con alfalfa y pastales de los cerros en un determinado sector, se desplazaban por un tiempo similar a otra área, repitiendo este ciclo constantemente mientras esperaban que la alfalfa creciera en sus potreros:

Mi papá se movía entre Socoroma y Murmuntani, tenía que llevar sus animales a
pastoriar, estaba allá 30-40 días, después se volvía, acá habia alfalfa, pastoriaba acá
[...] se acababa el pasto acá, entonces a los dos meses volvia pa'llá, porque en dos meses
crece el pasto. Entonces vuelta pa'llá con el ganado. De acuerdo a lo que se acabe el
pasto, cualquier fecha, dos meses, tres meses pueden pasar también (J.F.).

Se aprecia que el ganado, fundamentalmente ovino, se había constituido en un elemento relevante para la economía socoromeńa: permitía una ventajosa inserción en el mercado y además funcionaba como una especie de seguro ante dificultades económicas gracias a la facilidad con que podía ser convertido en dinero. La importancia que todavía tenía el ganado a inicios de los años ochenta puede verse en el trabajo realizado por Castro y Bahamondes (1987, 1988) respecto a la propiedad de la tierra en Socoroma, mostrando que la mayoría de los predios eran destinados a producir alfalfa, reflejando la preocupación de las familias por contar con forraje. ${ }^{8}$

Entre las localidades de Socoroma con el valle de Lluta. El patrón de ocupación en el valle es disperso, especialmente en los tramos altos, con Sora como el sector con mayor población nucleada, donde actualmente residen alrededor de 10 personas. Para los socoromeños este ha sido un piso ecológico importante porque el clima permitía, a diferencia de la precordillera, obtener dos cosechas de trigo y maíz en el año, productos requeridos para consumo familiar así como para intercambiar con los llameros altiplánicos. También el clima, junto con los espacios más abiertos y el curso permanente de agua, facilitaba el rápido crecimiento de alfalfa, producto cada vez más apetecido en vista del aumento del ganado. Acceder a los terrenos en Lluta fue de gran interés para las numerosas familias que manejaban grandes rebaños, ya que así podían obtener forraje cuando este escaseaba en la precordillera. En efecto, los datos permiten concluir que la reedición o intensificación de la complementariedad ecológica con el valle de Lluta durante el siglo XX fue impulsada por el aumento del ganado.

Esta complementariedad tomó forma de un doble domicilio con residencia temporal en Lluta. El ganado era conducido específicamente a los potreros del valle para consumir alfalfa:

Temporeros eran, pa' los cortes de alfalfa nomás, una vez al mes se bajaba. Un mes permanecian, se comía todo el pasto y después volvian a retornar [...]. Bajaban con los animales a vivir ahi, por eso hay casas. Corderos, vacunos habia esa vez también, los burros, caballos, machos (R.G.).

8 De un total de 182 predios analizados en residentes permanentes, 75 tenían cultivos de alfalfa, correspondientes a un $41,2 \%$; de 79 predios de residentes temporales, en 28 cultivaban alfalfa, correspondiente a un 35,4\% (Castro y Bahamondes, 1987, p. 51). 
Un socoromeño señalando la casa de su abuelo en Molinos explicaba:

Tenía casa en Socoroma y tenía acá [...] por los animales, te das cuenta los grandes espacios que hay para alfalfa, maiz, entonces les convenia tener, podian criar animales acá, bajaban con sus animales. Me acuerdo que me decia mi papá, que bajaba con las ovejas, desde arriba por el camino de Equejta, hasta Molinos, por ahi bajaban (J.M.).

La semilla de alfalfa, producto privilegiado, se llevaba a Socoroma con el objetivo de sembrar o intercambiar y más tardíamente comercializar, en virtud de la extendida necesidad forrajera:

Mi papá iba a ayudarle [al suegro] a cosechar y mi papá por el pago de eso se traía semilla, por ejemplo dos sacos de semilla, se cargaba su burro y se venia, en Socoroma era más alfalfa pa' él, o si no también vendia para pagar otros gastos (L.G.).

Por otra parte, la complementariedad con Lluta también adquirió características microverticales. Algunas personas en la década del sesenta bajaban desde Socoroma a regar sus sembradíos en Lluta y volvían al pueblo durante la misma jornada:

Por ejemplo de Socoroma yo partía a las cuatro de la mañana, aqui [Arancha] estaba seis y media, siete, y ponia el agua a mi maiz, y si es que dejaba [el agua] el vecino me lo botaba, me devolvía en el día, a las tres, cuatro de la tarde ya estaba en Socoroma de vuelta [...]. En la semana una vez, o bien se turnaban, por ejemplo esta semana el lunes bajabai tú, asi que me poniai al maizal mio, al tuyo; bajaba a la otra semana yo y ponía a los dos, asi se hacían su turno (E.V.).

Considerando el esfuerzo y gasto energético que implicaba transitar de un piso ecológico a otro durante el mismo día, surgía la necesidad de lograr acuerdos para facilitar el trabajo y optimizar los desplazamientos, arreglos particulares entre personas o familias de manera descentralizada, sin que las relaciones y la producción estuvieran normadas por autoridades comunitarias.

Extracción de guano en las covaderas. Muchos socoromeños tuvieron la necesidad de realizar viajes a las guaneras situadas en el área costera de Corazones y Anzota, con el objetivo de obtener fertilizante natural, indispensable para su agricultura. Esta actividad es entendida como acceso directo, ya que los propios socoromeños realizaban la extracción del recurso, pero con la distinción que no se ejercía un control de este o del territorio al que accedían, pues correspondía a propiedad fiscal.

Relata un socoromeño que realizó sus últimos viajes desde Socoroma en la década del sesenta:

Ahi en las guaneras nos encontrábamos hasta 60 burros, y seguian trayendo en el mes de septiembre [...]. Ahi sacamos el guano, sacamos con unas picotitas chicas, lo picamos en la mañana pa' sacar el día siguiente [...]. Llegamos en la mañana, dormimos ahi, al día siguiente veniamos a dormir a Azapa, cruzábamos por donde está la cárcel ahora, por ahi cruzábamos asi de frente a Azapa, ahi ya descansamos unos dos dias, no descargaba tampoco, se llevaba el guano a Arica para mandar por el ferrocarril un viaje [...]. El segundo viaje ya se iba con todo el guano pa' arriba, el primero se iba en el tren. Nosotros tenimos calculado qué día más o menos vamos a estar en Socoroma 


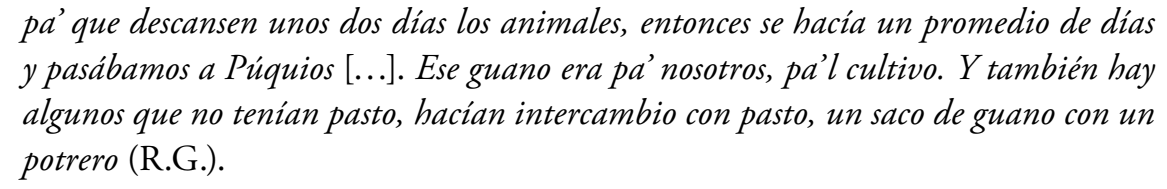

La descripción destaca que esta actividad fue extendida entre los arrieros indígenas, pues se juntaba gran cantidad de animales con el mismo fin. La frecuencia de los viajes estaba dirigida por el ciclo agrícola de la precordillera, centrándose especialmente en los meses de agosto y septiembre, cuando se inicia el período de siembra. La obtención del guano era realizada independientemente por cada individuo que llegaba con sus burros a las covaderas. Tras su obtención existía un interesante trabajo al enviar una carga por tren, para luego, tras haber dejado otra carga en Socoroma, dirigirse a la estación de Púquios a recogerla, demostrando una impresionante capacidad de desplazamiento y coordinación logística. Por último, entrega un dato interesante que permite entender la valoración del guano entre los serranos, al intercambiar en la comunidad un saco del fertilizante por un potrero de alfalfa.

Algunos socoromeños realizaban esta labor como parte de una economía de subsistencia familiar, destinando una fracción de la carga al abono de chacras propias y otra para efectuar intercambios en los valles de Lluta y Azapa, mientras que otros extraían guano para generar mayores recursos vendiendo el producto o intercambiándolo por terrenos cultivables en Socoroma.

Acceso indirecto. Un modo distinto para obtener recursos complementarios fueron los viajes con fines de intercambio, ya fuera mediante trueque o comercio, agrupados bajo la modalidad de acceso indirecto en la medida que los socoromeńos no participaban en la producción de los bienes o no tenían control sobre aquellos espacios productivos. Entre las diversas rutas utilizadas se encuentran las dirigidas a La Paz y a Potosí en Bolivia, a Tacna en Perú, a Púquios, Choqulimpe, Portezuelo, Codpa, Azapa y Arica en Chile. Los animales fueron cruciales en estos desplazamientos; en muchos casos el motivo del viaje era comercializar ganado y, en muchos otros, movilizar productos agrícolas y mercancías utilizando fuerza animal, desempeñándose como arrieros a corta y larga distancia. Actualmente ninguna de estas rutas es utilizada, la modernización de los medios de transporte y comunicación alteró las formas de desplazamiento y orientación de las rutas que comunicaban regionalmente el territorio.

Particular es la relación que los socoromeños establecieron con algunas poblaciones altiplánicas. Si bien corresponde a un caso de acceso indirecto, tiene la particularidad de que no se producía un desplazamiento desde su territorio, eran los llameros quienes arribaban a la precordillera o el valle para realizar los intercambios productivos.

Bolivia. Desde tiempos prehispánicos estuvieron integrados mediante diversas rutas los sectores que hoy se encuentran separados en el altiplano boliviano y la precordillera chilena (Chacama, 2005; Choque y Muñoz, 2016). De acuerdo a la memoria colectiva, parte del camino de la Ruta de la Plata se mantuvo hasta las primeras décadas del siglo XX, aun durante la ocupación chilena del territorio, cuando arrieros de Socoroma se desplazaban entre Arica y La Paz movilizando gran diversidad de mercancías, incluido el metálico entre instituciones financieras, lo que realizaban como iniciativa particular o mediante contrato con terceros. Cuando las restricciones al tráfico con Bolivia se intensificaron, la ruta fue perdiendo vigencia y hacia mediados del siglo XX dejó de ser un tránsito para el arrieraje. 
Ellos iban pa' Bolivia pue', con la carga, con los animales pue', por ejemplo de Europa venía la carga pa' Cochabamba, pa' La Paz, pa'Alto de La Paz; entonces iban a entregar las cargas, de allá venían cargados los animales con otras cosas también para mandar pa' Europa. Entregaban al Banco del Estado de Chile, esos se encargaban de mandar para Europa, entonces sabian mandar la plata en saco [...]. Es que Bolivia les pagaba pue', pa' que entregue, lo mismo que yo te mando un paquete pagado, la persona tiene que entregarte nomás. Entonces todo eso era ganancia $p a$ ' los arrieros pue'(E.G.).

Otro objetivo con el que viajaban a Bolivia fue conseguir ganado cuando este escaseaba en los sectores precordilleranos debido a la alta demanda generada desde lugares como Portezuelo, Choquelimpe, Central Chapiquiña, los regimientos militares. Los socoromeños realizaban extensos trayectos para introducir ganado cruzando las fronteras nacionales, lo que podían hacer, dependiendo del contexto, a través de pasos oficiales o huellas clandestinas.

Yo una vez traje de Bolivia, cerca de Oruro, como 24 vacunos trajimos con un primo, ese hicimos llegar hasta acá po', hasta el Liceo 5 donde estaba el matadero. Nos demoramos un dia, dos, tres, cuatro, cinco, seis, siete dias hasta llegar a Arica, lejos es [...]. En Caquena habia retén siempre, por entremedio de los dos Pallachatas pasábamos con los animales a Caquena, de Caquena a Putre, de Putre a Socoroma, de Socoroma a Lluta. [...] Además esos tiempos Chile no tenia mucho ganado, nosotros traíamos pa'l regimiento, entonces en los retenes chilenos teníamos que presentarnos con los animales, entonces asi pasamos hasta acá po' (R.G.).

Tacna. Este trayecto fue realizado hasta mediados del siglo XX a pesar de las restricciones impuestas por el Tratado de Ancón en 1929 que separó las provincias de Arica y Tacna en dos Estados diferentes, debido a que el paso oficial para controlar el flujo de personas y productos se estableció en el sector costero. Para algunas familias su función fue el abastecimiento ocasional de productos de autoconsumo, mientras que para arrieros fue la obtención de mercancías que intercambiaban o comercializaban en los pueblos serranos. El viaje se programaba dependiendo de la información disponible respecto al valor de los productos llevados desde Socoroma y las mercancías adquiridas en Perú. Si bien el tiempo fue menor que el requerido para llegar a Arica, solo un porcentaje reducido de personas privilegiaba esta ruta, la mayoría se dirigía por Lluta reactivando relaciones de complementariedad mantenidas en el valle.

\begin{abstract}
Cuando yo comencé a acompañar a mi padre en sus viajes el punto de abastecimiento más cercano y más común era Tacna, no era Arica, porque uno salía de Socoroma, un día y una noche ya estaba en la parte alta de Tacna. Es directo, Socoroma, la estación de Púquios, hacia el norte y se bajaba por el sector Pachia, ahi se llegaba a alojar con la recua de animales, se dejaban los animales en Pachia, y se bajaba de ahi en carreta a Tacna. Estoy hablando del año 55. Entonces mi padre compraba toda su mercadería en Tacna y se venía a Socoroma. A diferencia de venir a Arica era un día más. Eso era muy común. Mi tío S. un tiempo vivia en Tacna y un tiempo en Socoroma, un tiempo acá y un tiempo allá (F.H.).
\end{abstract}

Los últimos registros de viajes hacia Tacna son de la década de 1950, posteriormente la recién construida carretera 11-CH comenzó a canalizar los desplazamientos a la ciudad de Arica. 
Estación Púquios. Este camino era utilizado como parte del trayecto a Tacna, sin embargo cuando se construyó la estación Púquios del ferrocarril Arica-La Paz, se transformó en una ruta que muchos socoromeños realizaron para dirigirse a Arica al reducir el tiempo de desplazamiento e implicar menor desgaste físico, y sobre todo para comercializar los productos requeridos por los trabajadores del campamento ferroviario, entre los que destacaba la producción ganadera: "Mi papá para Púquio llevaba por cajones queso, haciamos queso nosotros, de la leche del chivato, de la oveja, de la vaca" (E.G.). "Es que la estación eran trabajadores del ferrocarril, era un campamento más que nada, asi que ellos le abastecian de alimentos, huevos, gallinas, un cordero, un vacuno"(L.G.).

Arica. Antes que se construyera el ferrocarril y luego la Ruta 11-CH, caminando y montados en animales los socoromeños realizaban el trayecto a la ciudad para abastecerse de mercancías. De la precordillera descendían con productos livianos como orégano, chuño, retaña o carbón, y especialmente ganado para proveer la urbe de carne ovina y vacuna. Este se engordaba hasta tener un número considerable de animales, con los que se dirigían por Lluta aprovechando sus domicilios o activando relaciones de parentesco para descansar y alimentar los animales antes de ser entregados en los mataderos que hasta los años setenta funcionaron en Arica.

Veniamos a Arica a comprar. Habia que venir por lo menos pa' comprarse unos cinco
sacos de arroz, cinco sacos de azúcar, seis cajas de fideos, 10 litros de aceite, y asi po',
todo en cantidad. Y bajábamos con unos 80 corderos. Toíto los vendíamos [...]. No-
sotros llegábamos hasta Lluta en el día, y ahí nos quedábamos, al otro día partíamos
temprano, a las seis de la mañana estábamos cruzando el cerro [hacia Azapa]. En
Lluta nos quedábamos donde conocidos, familia, yo tengo harta familia en Lluta, los
G., los H., y ahí habia corrales (C.G.).

Es importante destacar que hasta esa década la demanda de carne de Arica era abastecida principalmente por los pueblos serranos de la región.

Choquelimpe, Portezuelo, Central Chapiquiña. ${ }^{10}$ La mina de Choquelimpe se ubica en el altiplano, sobre los $4000 \mathrm{msnm}$, traspasando la cordillera de Chapiquińa. A pesar de que su explotación se remonta a tiempos prehispánicos y funcionó durante la Colonia, no se identificaron memorias asociadas a esos períodos; estas se inscriben a fines del siglo XIX y comienzos del XX. La mina atrajo a muchos socoromeños para labores de construcción y explotación del mineral, pero también para compraventa de mercancías. La constante demanda de alimentos producida por los trabajadores era suplida en parte por la población socoromeña con productos agrícolas y ganaderos, a la vez que se beneficiaban consiguiendo diversidad de abarrotes. En menos de seis horas desde Socoroma y tres desde Zapahuira o Murmuntani se alcanza el campamento minero. "Todos los agricultores de Socoroma antes iban a vender sus productos a la mina, a Choquelimpe iban a vender, el choclo, chuño, zapallo, la papa. Y alojaban en la casa de mi abuela. Llegaban de Zapahuira, de Socoroma, de Codpa" (N.C.).

9 También llamada pincu pincu, la retańa es una raíz que crece en los cerros y que fue utilizada profusamente para la curtimbre gracias a su pigmentación.

10 Un aspecto que destacan los relatos y que sobrepasa los marcos del presente estudio, es la denuncia contra la Central Hidroeléctrica Chapiquińa que a fines de los años sesenta produjo una dramática reducción del curso de agua en la quebrada de Murmuntani, forzando la migración de numerosas familias socoromeñas de Murmuntani, Epispacha y Chusmiza. 
Por su parte, Portezuelo fue un campamento de trabajadores creado a fines de los cincuenta en el cerro Churilinco para la obra de canalización del río Lauca hacia el valle de Azapa. Este lugar también se estableció como un punto relevante de intercambio y comercio, acudiendo desde las distintas localidades del territorio comunitario. "Acá arriba en Portezuelo habia un campamento grande y estaban trabajando, entonces allá mismo iba a vender. De allá mismo me traía la azúcar, el arroz, porque ellos traian por saco, en la pulperia que habia, entonces ahi los cambiaba por queso" (B.A.).

Asimismo, cuando se terminó la obra y comenzó a funcionar la Central Hidroeléctrica de Chapiquiña, continuó la demanda de productos serranos, especialmente de carne: "Yo llevaba vacuno de Belén, iba a caballo, con mulas, macho. Comprábamos en Belén, algunos hacíamos engordar, algunos no, el dinero tira, los entregábamos a la Central de Chapiquiña" (M.Q.).

Azapa. En momentos específicos del año viajaban para obtener productos del valle, como aceitunas o cańa de azúcar, y para asistir a la Fiesta de las Peñas en octubre y diciembre, instancias propicias para vender una importante cantidad de ganado motivada por las necesidades de los feligreses. Faenando los animales de acuerdo a los requerimientos diarios de los puesteros de comida, en pocos días algunos socoromeños liquidaban sus rebaños.

Iba con mi marido, 50 corderos llevaba de Putre. Ganaba plata, como papel traíamos la plata, y eso lo ocupábamos para comprar mercadería, guano para las chacras. Hace como 15 años que no voy, ibamos a la fiesta grande y a la fiesta chica. Demorábamos casi dos días. De acá nos íbamos con el ganado y allá nos quedábamos en Livilcar, allá descansábamos, y de ahi nos íbamos hasta las Peñas (J.G.).

La estrategia del matrimonio es interesante por las conversiones que experimentaban los bienes, movilizados constantemente para conseguir beneficios. Desde Putre, donde alquilaban terreno, salían con corderos propios y otros comprados con fines comerciales; en las Peñas eran vendidos y carneados personalmente, convirtiéndolos en dinero; esta ganancia monetaria luego era invertida en guano llevado a Socoroma por otros arrieros del pueblo; con el fertilizante abonaban los terrenos para sus cultivos, tanto chacras como potreros de alfalfa, cerrando el círculo en relación a la ganadería. A través de este circuito económico, para muchas familias la peregrinación religiosa de Las Peńas se convirtió en un importante momento de comercio, dinamizando el conjunto de la actividad económica.

Otros llegaban a Azapa buscando productos específicos del lugar, como el caso del padre de E.G., de oficio arriero, quien a su vez cargaba desde Socoroma productos derivados de la ganadería: "Para Azapa llevaba queso por cajones, decía entonces: ¿ Ustedes quieren comer aceituna, quieren comer camote, quieren chupar caña? Ya, hagan queso como corresponde', y asi nosotros tomábamos menos leche y haciamos harto queso pue’ [...]. Traía verde, recién sacado, si pue’, cambiaba con el queso pue, la gente harto traía aceituna".

Codpa. Una de las rutas más comunes y transitadas fue hacia el sur por la precordillera, utilizando el Camino del Inca ${ }^{11}$ que atraviesa longitudinalmente los cordones serranos (Santoro et al., 1987) para llegar al pueblo de Codpa, ubicado alrededor de $2000 \mathrm{msnm}$ en el valle de Camarones. El trayecto normalmente tomaba dos a tres días de viaje. Al cabo de una semana

11 Hoy está siendo promovido turísticamente desde instituciones estatales como Qhapac Nan, modificando el nombre que le han dado tradicionalmente los socoromeños. 
los viajantes estaban de regreso con productos que se daban en un clima más cálido, especialmente frutas como membrillos, uvas, peras, manzanas, duraznos, "orejones" y el famoso vino "pintatani". Este último cumplía múltiples objetivos: consumo personal, requerimientos rituales y comercio con otros pueblos, como ejemplifica F.H.: "A Codpa habia que ir por dos razones, la gente de los distintos pueblos de Ticnámar hasta Putre, una en la época de fruta, entonces iban con las tropas de mulas con angarilla a buscar fruta, sobre todo pa' los carnavales, y la otra fecha era cuando salia el vino pintatani, generalmente como en agosto, por ahi iban al vino".

En consideración a la distancia geográfica, la importancia de los productos intercambiados y la menor intensidad en las relaciones de parentesco entre ambos sectores, era necesario incentivar la perduración de estos flujos mediante pautas institucionalizadas de hospitalidad, como destaca el siguiente relato que a un socoromeño le comunicara su padre:

Mi papá viajaba -dijo, me contaba de que habia viajado con su papá a Codpa-, iban a buscar fruta, y ellos llevaban papas, maiz, chuño, y que la gente de Codpa quería mucho a la gente de Socoroma, apreciaba mucho. Decía: "Pucha, en cada parcela sacaban asi un plato, bandeja, y sacaban con los mejores racimos, con los mejores membrillos, y ese nos recibia de esa forma - dijo-, a toda la gente que iban de acá, y se peliaban por recibirnos"-dijo-(L.G.).

Altiplano. Este tipo de relación complementaria es distinta a las anteriores desde el punto de vista de la movilidad. Los socoromeños no transitaban hacia otros pisos ecológicos, eran los llameros quienes descendían desde las altas mesetas para intercambiar sus productos, principalmente charqui, coca, telas, carne, regresando a la puna con papas, chuño y maíz.
De más arriba de Putre, de Parinacota, Chucuyo, Caquena, venian con un grupito de llamos a Socoroma [...]. Era como que vivia una semana en Socoroma el caballero, y diario iba carniando uno, si habian más interesados carniaba también otro. Y tam- bién como carniaba iba recibiendo la papa, el chuño, iba vendiendo chalinas, paños, sogas, y decía "vale tanto, tanto", y la gente le iba juntando su mercadería (L.G.).

El arribo de los llameros ocurría en el primer semestre del año, después de las lluvias y hasta el período de las heladas, es decir, desde abril con las salidas tempraneras de la papa, pasando por mayo con la abundancia del maíz y papa, hasta julio cuando se producía chuño. También llegaban a Lluta donde podían proveerse con mayor variedad y calidad de productos.

Las relaciones con los pastores del altiplano, al igual que en Codpa, eran sostenidas bajo principios de reciprocidad y hospitalidad, siendo bienvenidos en virtud de los beneficios que reportaban al conjunto de la comunidad. En algunos casos se daban relaciones de compadrazgo con familias del altiplano que aseguraban la provisión de carne en determinados momentos del año. Según L.G.: "Mi mamá tenía unas madrinas de allá de Parinacota, una señora se llamaba F.V., 'ella era mi madrina' dice, cuando llegaban seguro acá y tenian guagüita con el pelo largo y le cortaban el pelo o lo bautizaban, 'asi que era mi madrina' dice, 'después mi madrina cada vez que venía me traía carne' dice". A su vez, cuando su madrina regresaba a Parinacota era despachada con productos de Socoroma.

Esta modalidad corresponde a un acceso indirecto en el sentido de que no existía control de los socoromeńos sobre los recursos a los que accedían, recibiendo en su territorio a la población 
que llegaba con el objetivo de intercambio, prescindiendo así de la movilidad característica en sus relaciones complementarias.

\section{Conclusiones}

La complementariedad ecológica, si bien tiene un fundamento en elementos de la geografía, debe entenderse como un producto histórico de las poblaciones andinas, las que a partir de patrones comunes de comportamiento han elaborado diversas estrategias de sobrevivencia. Una característica esencial ha sido su dinamismo, de acuerdo a Salomon (1985, p. 521): "by 'complementary' we should not understand a permanent essence of Andean societies, but a collective project continually renewed through processes of adjustment, mobilization, innovation, and conflict”. Desde una perspectiva diacrónica se ha destacado la continuidad en la ocupación del territorio socoromeño, manteniendo como constante una forma de habitar el espacio caracterizada por la movilidad. En efecto, durante el siglo XX el mecanismo que permitió integrar el territorio bajo un sistema de complementariedad fue la amplia movilidad desplegada por los socoromeńos, articulando desde su comunidad el vasto espacio macrorregional. Esta movilidad estuvo orientada principalmente por la obtención de recursos, mediante dos mecanismos principales relacionados con la participación en la producción de los bienes: acceso directo y acceso indirecto, ya fuera manteniendo control, o no, sobre el territorio donde se accedía a los productos.

El acceso directo operó principalmente en una dimensión comunitaria. La mayoría de las familias socoromeñas han mantenido tierras y derechos de usufructo en las distintas localidades del territorio comunitario y participan directamente en la producción de los bienes agrícolas y ganaderos. En el valle de Lluta, cuyas interacciones se reeditaron en diferentes contextos históricos, distintas familias eran propietarias de tierras y las utilizaban de manera temporal para aprovechar diferenciadamente el ciclo agrícola y la producción semillera de alfalfa. Un caso especial fue el establecido en la zona costera de Arica para acceder al guano de las covaderas, producto que los socoromeños obtenían con sus propias manos, pero cuyo territorio era ajeno a su propiedad.

El acceso indirecto se realizaba preferentemente en lugares situados fuera del territorio comunitario. Al carecer de control sobre el territorio, acudían con su producción agroganadera para realizar intercambios mediante trueque en Codpa, las estaciones del ferrocarril o Choquelimpe, o establecer relaciones comerciales cuando frecuentaban las ciudades, ya fuera en Chile, Perú o Bolivia, cuyas travesías podían durar meses. En ellos participaban dos tipos de actores, quienes efectuaban los viajes para vender su ganado y surtir de bienes complementarios a sus familias, y quienes los hacían con fines esencialmente comerciales, obteniendo ganancias mediante el traslado de productos entre distintas zonas productivas. Al igual que en el mecanismo anterior, se observa un caso especial: en la relación establecida con las poblaciones altiplánicas el desplazamiento no era realizado por socoromeños, sino por los llameros, quienes arribaban con fines principalmente de intercambio.

Algunos elementos de casos estudiados en otros momentos históricos y otras regiones de los Andes permiten evidenciar que se practicaron simultáneamente distintos modos de complementariedad. Las características del valle de Lluta y la corta distancia que lo separa de la precordillera facilitó una estrecha relación entre los pisos ecológicos, donde se practicó una estructura vertical de tipo compacto como planteara Brush (1987). A su vez, se ejercía una microverticalidad 
del tipo propuesto por Oberem (1981), ya que muchos socoromeños trascendían los límites de los pisos ecológicos durante una misma jornada, lo que cuestiona el descarte de prácticas microverticales en tiempos precolombinos realizado por Santoro et al. (2010, p. 336) entre sectores precordilleranos y el chaupiyunga del valle de Lluta (Molinos, Sora, Arancha). También se observan características del archipiélago horizontal según las ideas de Rostworowski (1977) y especialmente Shimada (1982), pues mediante los desplazamientos que atravesaban longitudinalmente el sector serrano eran articuladas tres quebradas adyacentes que integran el territorio comunitario (Socoroma, Río Seco y Murmuntani). La disposición vertical y horizontal de la complementariedad era combinada a lo largo del año. Entre estas relaciones complementarias se daban situaciones de doble domicilio, como fuera planteado por Harris (1978), manteniendo una o más residencias de uso temporal con fines productivos.

Se constata que durante el siglo XX las relaciones de complementariedad fueron descentralizadas, ejercidas a nivel familiar o unidades domésticas, sin la existencia de regulaciones por parte de autoridades comunales. Aunque fueron prácticas extendidas entre las familias de la comunidad, no constituye un sistema homogéneo, pues las formas de ocupar el territorio, los desplazamientos y ciertos tipos de relaciones sociales estuvieron diferenciados según distintas familias. En este sentido, fue clave la mantención de relaciones de parentesco en el territorio, ya fuera al interior de la comunidad, donde las redes parentales son más evidentes, o con poblaciones asentadas en otros pisos ecológicos, donde las relaciones debían ser constantemente validadas, tendiendo a institucionalizarse mediante mecanismos de compadrazgo.

La investigación ha destacado la actividad pastoril de la población socoromeña. Medinacelli (2010, p. 18) define a los pastores andinos, junto con su esencial movilidad, como "aquel grupo que, aunque realice algún trabajo agrícola, la parte más importante de su economía y el espacio que habita la mayor parte del año se consagran al cuidado y uso de los animales". Para el caso de Socoroma es difícil diferenciar con precisión el tiempo destinado a la agricultura y a la ganadería. Durante el transcurso del siglo XX casi la totalidad de las familias socoromeńas poseían ganado y practicaban una fuerte integración de ambas actividades, motivo del título de este trabajo, pues los socoromeños a lo largo del siglo pasado fueron tan activos pastores como agricultores, lo que contrasta con la visión extendida que ha entendido la complementariedad agropastoril basada en las relaciones establecidas por grupos sociales diferenciados de agricultores y pastores (Duviols, 1973; Medinacelli, 2010). El ganado formaba parte del proyecto familiar en el contexto de la experiencia socoromeña. Todos los nińos eran pastores; tras el colegio debían pasar largas horas en los cerros pasteando los corderos o caminar varios días buscando los vacunos dejados temporalmente en los cerros. Así también muchos recuerdan sus primeros años viajando en las angarillas de los burros cuando sus padres se desplazaban en busca de forraje para los animales. Caballos, burros y mulas criaban los socoromeńos para desplazarse y transportar sus productos desde los distanciados sectores de cultivo que caracterizan el paisaje agrícola serrano; también para practicar la arriería, principalmente como una forma de complementar su economía familiar. La mayoría de las unidades domésticas poseían distintos tipos de ganado y combinaban diferentes mecanismos de movilidad asociados a ellos. Tanto las necesidades forrajeras como la movilidad que permiten los animales impelieron a intensificar las relaciones de complementariedad en la articulación de diferentes ecologías.

Los datos etnográficos permiten sostener la hipótesis de que la actividad ganadera provocó la ampliación y constricción de los sistemas de complementariedad ecológica durante el siglo XX. Estas oscilaciones tuvieron directa relación con la comercialización de ganado, demanda que se incrementó o se contrajo según contextos regionales favorables o desfavorables, respectivamente. 
Su intensificación estuvo asociada a la dinamización económica experimentada por la región a mediados del siglo XX cuando Arica se convirtió en polo de desarrollo y por tanto de atracción demográfica, generando un importante requerimiento de alimentos, carne entre los principales, que en gran medida fue suministrada por las poblaciones precordilleranas con su producción de ganado ovino y vacuno. El contexto regional fue favorable al carecer de una conexión vial fluida con el sur del país, distanciando los períodos de arribo del producto, sumado a la dificultad para su conservación en la ciudad que facilitaba su pronto consumo. Así, los socoromeños percibían un estímulo para aumentar la crianza de ganado, el que presionaba sobre los recursos forrajeros de cada localidad, fomentando el desplazamiento entre los distintos asentamientos de la precordillera y el valle de Lluta. El ferrocarril produjo un efecto similar, las estaciones dispuestas en diversos puntos de la región funcionaron como pequeños nodos de intercambio y venta de productos, especialmente carne por parte de los socoromeńos. Los viajes realizados a diferentes sectores de Bolivia para adquirir animales que luego vendían demuestra que diversos contextos dinamizaban sus relaciones de complementariedad provocando la intensificación de sus movimientos en el territorio. Asimismo, la constricción de la movilidad se relaciona con la disminución en la demanda ganadera. En la década del sesenta cambios tecnológicos propiciaron el arribo de carne congelada a Arica, generando el decaimiento del negocio ganadero en la región. A su vez la construcción de la Carretera Internacional afectó los puntos de demanda más cercanos, Choquelimpe y Central Chapiquińa, que desde ese momento comenzaban a ser abastecidos mediante frigoríficos, lo que se aprecia en el siguiente comentario de R.G.: "Cuando ya comenzó a entrar los camiones desde Arica a Zapahuira, porque de Zapahuira pa' arriba se internaban llevando carga [...] ;Buuu!, la carretera cambió todo, por eso que en Socoroma todos vendieron sus animales".

De esta manera, mientras la demanda de carne se mantuvo alta, los socoromeńos desplegaron sus mecanismos de complementariedad en constantes movimientos para alimentar su ganado, pero cuando esta comenzó a decaer, los desplazamientos, en función del forraje para los animales, se hicieron cada vez más distantes. El sistema de complementariedad de los socoromeños fue decayendo en la medida que su producción local era reemplazada por aquella abastecida desde la zona centro-sur del país. Sin desconocer que la migración masiva a la ciudad a partir de la década del sesenta influyó fuertemente disminuyendo la intensidad de estas formas de movilidad en el territorio, se sostiene que la tenencia de ganado fue el elemento central en la constricción y ampliación de las relaciones de complementariedad ecológica trazadas por las familias socoromeñas a lo largo del siglo XX.

\section{Referencias citadas}

Berenguer, J. y Dauelsberg, P. (1997 [1989]). El Norte Grande en la órbita de Tiwanaku (400 a 1.200 d.C.). En Hidalgo, J. et al. (Eds.). Prehistoria. Desde sus origenes hasta los albores de la conquista (pp. 129-180). Santiago: Andrés Bello.

Browman, D. (1980). Tiwanaku expansion and altiplano economic patterns. Homenaje al VII Congreso de Arqueología Chilena. Estudios Arqueológicos, 5, 107-120.

Brush, S. (1987 [1974]). El lugar del hombre en el ecosistema andino. En El Ecosistema Andino (pp. 69-101). La Paz: Hisbol.

Camino, A. (1982). Tiempo y Espacio en la Estrategia de Subsistencia Andina: un Caso en las Vertientes Orientales Sud-Peruanas. Senri Ethnological Studies, 10, 11-38. 
Castro, M. y Bahamondes, M. (1987). Cambios en la tenencia de la tierra en un pueblo de la precordillera del Norte de Chile: Socoroma. Revista Chilena de Antropología, 6, 35-57.

Castro, M. y Bahamondes, M. (1988). Control de la tierra en la cabecera del Valle de Lluta. Revista Chilena de Antropología, 7, 93-113.

Cerna, C. y Muñoz, W. (2019). Movilidad, parentesco e identificación en el Valle de Codpa, Norte de Chile. Chungara. Revista de Antropología Chilena, 51(4), 661-674.

Chacama, J. (2005). Patrón de asentamiento y uso del espacio. Precordillera de Arica, extremo norte de Chile, siglos X-XV. Boletín del Instituto Francés de Estudios Andinos, 34, 357-378.

Choque, C. y Muñoz, I. (2016). El Camino Real de la Plata. Circulación de mercancías e interacciones culturales en los valles y Altos de Arica (siglos XVI al XVIII). Revista Historia, 49(1), 57-86.

Condarco, R. (1971 [1987]). El escenario andino y el hombre. En La Teoría de la Complementariedad Vertical Eco-simbiótica (pp. 7-28). La Paz: Hisbol.

Dauelsberg, P. (1992-1993). Prehistoria de Arica. Diálogo Andino, 11-12, 10-31.

Durston, A. e Hidalgo, J. (1997). Presencia andina en los valles de Arica, siglos XVI -XIII: casos de regeneración colonial de estructuras archipielágicas. Chungara, 29(2), 249-273.

Duviols, P. (1973). Huari y Llacuaz. Agricultores y Pastores. Un dualismo prehispánico de oposición y complementariedad. Revista del Museo Nacional, XXXIX, 153-191.

García, M. y Ajata, R. (2016). Arqueología y memoria de los caminantes de la precordillera de Camarones, Sierra de Arica. Diálogo Andino, 49, 235-247.

Gölte, J. (1980). La racionalidad de la organización andina. Lima: IEP Ediciones.

Gölte, J. y De la Cadena, M. (1986). La codeterminación de la organización social andina. Documento de Trabajo $\mathrm{N}^{\circ} 13$. Instituto de Estudios Peruanos.

González, H., Gundermann, H. e Hidalgo, J. (2014). Comunidad indígena y construcción histórica del espacio entre los aymara del norte de Chile. Chungara. Revista de Antropología Chilena, 46(2), 233-246.

Gundermann, H. (2001). Procesos regionales y poblaciones indígenas en el norte de Chile. Un esquema de análisis con base en la continuidad y los cambios de la comunidad andina. Estudios Atacameños, 21, 89-112.

Gundermann, H. y Vergara, J. (2009). Comunidad, organización y complejidad social andinas en el norte de Chile. Estudios Atacameños. Arqueología y Antropología Surandinas, 38, 107-126.

Harris, O. (1978). El parentesco y la economía vertical en el ayllu Laymi. Avances. Revista boliviana de estudios históricos y sociales, 1, 51-64.

Hidalgo, J. y Focacci, G. (1986). Multietnicidad en Arica, S. XVI. Evidencias etnohistóricas y arqueológicas. Chungara, 16-17, 137-147.

Hidalgo, J., Arévalo, P., Marsilli, M. y Santoro, C. (1988). Padrón de la Doctrina de Belén en 1813: Un caso de complementariedad tardía. Documento de Trabajo N4. Universidad de Tarapacá. 
Hidalgo, J. y Durston, A. (1998 [2004]). Reconstitución étnica colonial en la sierra de Arica: El cacicazgo de Codpa, 1650-1780. En Hidalgo, J. (Ed.). Historia Andina en Chile (pp. 507-534). Santiago: Universitaria.

Horta, H. (2015). El Señorio Arica y los Reinos Altiplánicos (1000-1540 d.C.). Complementariedad ecológica y multietnicidad durante los siglos pre-conquista en el norte de Chile. Santiago: Qillqa - Ocho Libros Editores.

Inostroza, X. (2010). Sociedad indigena en su interrelación con la sociedad colonial en la Provincia de Arica. Segunda mitad del siglo XVIII. Tesis de Magíster en Historia. Mención Etnohistoria. Universidad de Chile, Santiago, Chile.

Inostroza, X. (2011). Diferenciación social y liderazgo en comunidades andinas: Los 'Principales' de Belén y Socoroma: 1750-1799. Diálogo Andino, 38, 35-43.

Llagostera, A. (1976). Hipótesis sobre la expansión incaica en la vertiente occidental de los Andes meridionales. En Homenaje al Dr. Gustavo Le Paige, s.j., 71-81. Universidad del Norte.

Llagostera, A. (2010). Retomando los límites y las limitaciones del "archipiélago vertical”. Chungara. Revista de Antropología Chilena, 42(1), 283-295.

Lumbreras, L. (1974). Los Reinos Post-Tiwanaku en el área altiplánica. Revista del Museo Nacional, XL, 55-86.

Marcus, G. (2001). Etnografía en/del sistema mundo. El surgimiento de la etnografía multilocal. Alteridades, 11(22), 111-127.

Masuda, S. (Ed.). (1981). Estudios etnográficos del Perú Meridional. Tokio: Universidad de Tokio.

Mayer, E. (1994). Recursos naturales, medio ambiente, tecnología y desarrollo. En Dancourt, O., Mayer, E. y Monje, C. (Eds.). Perú: el problema agrario en debate - SEPIA V (pp. 479-533). Lima: Publicaciones Sepia.

Mayer, E. y Fonseca, C. (1988). Comunidad y Producción en la agricultura andina. Lima: Fomciencias.

Medinacelli, X. (2010). Sariri: Los llameros y la construcción de la sociedad colonial. La Paz: IFEA - Plural editores - Asdi - Instituto de Estudio Bolivianos.

Méndez-Quiróz, P. y García, M. (2018). Territorialidad, flujos espaciales y modalidades de tránsito yuxtapuestas en la red vial de los Valles Occidentales (siglos X-XX). Revista Transporte y Desarrollo, 18, 40-69.

Mujica, E., Rivera, M. y Lynch, T. (1983). Proyecto de estudio sobre la complementariedad económica Tiwanaku en los valles occidentales del centro-sur andino. Chungara, 11, 85-109.

Muñoz, I. (1997 [1989]). El periodo formativo en el Norte Grande. En Hidalgo, J. et al. (Eds.). Prehistoria. Desde sus origenes hasta los albores de la conquista (pp. 107-128). Santiago: Andrés Bello.

Muñoz, I., Chacama, J., Espinosa, V. y Briones, M. (1987). La ocupación prehispánica tardía en Zapahuira y su vinculación con la organización social y económica inca. Chungara, 18, 67-89.

Muñoz, I. y Choque, C. (2013). Interacción y cambio social: un relato arqueológico e histórico sobre las poblaciones que habitaron los valles precordilleranos de Arica durante los siglos X al XVII d.C. Revista Historia, 46(2), 421-441.

Murra, J. (1975). Formaciones económicas y políticas del mundo andino. Lima: IEP Ediciones. 
Niemeyer, H. (1997 [1989]). El escenario geográfico. En Hidalgo, J. et al. (Eds.). Prehistoria. Desde sus origenes hasta los albores de la conquista (pp. 1-12). Santiago: Andrés Bello.

Núñez, L. (1997 [1989]). Hacia la producción de alimentos y la vida sedentaria. En Hidalgo, J. et al. (Eds.). Prehistoria. Desde sus orígenes hasta los albores de la conquista (pp. 81-108). Santiago: Andrés Bello.

Núñez, L. y Dillehay, T. (1995 [1979]). Movilidad giratoria, armonia social y desarrollo en los Andes Meridionales: Patrones de Tráfico e interacción económica. Antofagasta: Universidad Católica del Norte.

Oberem, U. (1981 [1976]). El acceso a recursos naturales de diferentes ecologías en la sierra ecuatoriana (siglo XVI). Instituto Otavaleño de Antropología, 20, 45-71.

Platt, T. (1975). Experiencia y experimentación: Los asentamientos andinos en las cabeceras del Valle de Azapa. Chungara, 5, 33-60.

Platt, T. (1980 [1971]). Espejos y Maíz: el concepto de yanantin entre los Macha de Bolivia. En Mayer, E. y Bolton, R. (Eds.). Parentesco y Matrimonio en Los Andes (pp. 139-147). Lima: Fondo Editorial de la Pontificia Universidad Católica del Perú.

Rivera, M. (1975). Una hipótesis sobre movimientos poblaciones altiplánicas y transaltiplánicas en las Costas del Norte de Chile. Chungara, 5, 7-31.

Rivera, M. (1995-1996). Arica en las rutas de tráfico de Potosí: Algunas consideraciones sobre la sociedad andina del siglo XVIII. Revista Chilena de Antropología, 13, 99-136.

Romero, Á., Santoro, C. y Santos, M. (1998). Asentamientos y organización sociopolítica en los tramos bajo y medio del valle de Lluta. Actas del Tercer Congreso Chileno de Antropología, II, 696-706.

Rostworowski, M. (1977). Pescadores, artesanos y mercaderes costeños en el Perú prehispánico. En Etnía y sociedad. Costa peruana prehispánica (pp. 211-260). Lima: IEP Ediciones.

Ruz, R. (2008). Uso de pastales y construcción de circunscripciones comunitarias en la precordillera de Arica. Siglos XIX-X. Diálogo Andino, 31, 47-65.

Ruz, R., Galdames, L. y Díaz, A. (2010). Historia, patrimonio y fotografía de la Junta de Adelanto de Arica (1958-1976). Exploraciones teórico-metodológicas. En Díaz, A. y Pizarro, E. (Comps.). Arica Siglo XX. Historia y Sociedad en el extremo norte de Chile (pp. 101-130). Arica: Ediciones Universidad de Tarapacá.

Saignes, T. (1991). Lobos y ovejas. Formación y desarrollo de los pueblos y comunidades en el Sur Andino (Siglos XVI-XX). En Moreno, S. y Salomon, F. (Eds.). Reproducción y Transformación de las Sociedades Andinas, Siglos XVI-XX (pp. 91-35). Quito: Ediciones Abya-Yala.

Saintenoy, T., Ajata, R., Romero, A. y Sepúlveda, M. (2017). Arqueología del territorio aldeano prehispánico tarío en los altos de Arica: Aporte de la fotointerpretación satelital para el estudio regional de la cuenta alta de Azapa. Estudios Atacameños. Arqueología y Antropología Surandinas, 54, 85-109.

Salomon, F. (1985). The dynamic potential of the complementarity concept. En Masuda, S., Shimada, I. y Morris, C. (Eds.). Andean Ecology and Civilization. An Interdisciplinary Perspective on Andean Ecological Complementarity (pp. 511-531). Tokyo: University of Tokyo.

Santoro, C. et al. (2010). Revisita al tercer caso de verticalidad de John Murra en las costas de los Andes Centrales y Centro Sur. Chungara. Revista de Antropología Chilena, 42(1), 325-340. 
Santoro, C., Hidalgo, J. y Osorio, A. (1987). El Estado Inka y los grupos étnicos en el sistema de riego de Socoroma. Chungara, 19, 71-92.

Santoro, C., Romero, Á., Standen, V. y Torres, A. (2004). Continuidad y cambio en las comunidades locales, períodos intermedio tardío y tardío, valles occidentales, áreas centro sur andina. Chungara, Revista de Antropologia Chilena, 36, 235-247.

Shimada, I. (1982). Horizontal Archipelago and Coast-HighIand Interaction in North Peru: Archaeological Models. Senri Ethnolgical Studies, 10, 137-210.

Troll, C. (1958 [1987]). Las culturas superiores andinas y el medio geográfico. En El Ecosistema Andino (pp. 7-67). La Paz: Hisbol.

Wachtel, N. (1973). Sociedad e Ideología. Ensayos de historia y antropología andina. Lima: IEP Ediciones.

Webster, S. (1971). An indigenous quechua community in explotation of multiple ecological zones. Revista del Museo Nacional, XXXVII, 174-183. 